\title{
Investigation of Factors Influencing the Structural Vibration in Ball Bearings
}

\author{
KAPIL MEHRA, KAMBIZ FARHANG* and JAYANTA DATTA \\ Department of Mechanical Engineering and Energy Processes, Southern Illinois University at Carbondale, \\ Carbondale, IL 62901-6603, USA
}

(Received 13 October 1998; In final form 13 December 1998 )

\begin{abstract}
Hertzian equation for elastic contact is utilized along with lumped parameter approach to obtain the equations that govern the structural vibration of ball bearings. The lumped parameter formulation is obtained by treating various elements with mass lumped at their centers of gravity and the contact as nonlinear springs with nonlinear spring rates.

Effects of preload, ball rotational speed, and damping are studied using the formulation. It is found that in the presence of preload, irrespective of the load magnitude, contact is maintained with both the inner and the outer races. Hence, responses obtained with and without the check for ball/inner race and ball/outer race interferences are identical. In addition, no appreciable change is observed in the responses when the preload value is varied from 1 to $10 \mathrm{~N}$. At high speed of operation, the balls are found to maintain contact with the outer ring, whereas intermittent contact with the inner ring occurs for brief periods of time. Introduction of lubricant is found to dampen the oscillations considerably.
\end{abstract}

Keywords: Bearing, Vibrations, Dynamics, Structural, Preload

\section{INTRODUCTION}

Rolling element bearings are being used extensively in numerous mechanical systems. They find their use in relatively simple applications in electric motors and compressors to demanding applications in turbines and jet engines. In rolling element bearings, contact deformation is the result of loads that develop between the rolling elements and the inner or outer rings of the bearing. The motion of the balls/rollers relative to the line of action of an external load causes fluctuation in the apparent rigidity of the bearing. This phenomenon is commonly referred to as varying compliance and is known to be the primary cause of vibration in bearings. There are many other factors apart from varying compliance that contribute to vibration in bearings: varying roller diameter, misalignment, fit, surface roughness, flexibility of rotor shaft, etc.

Sunnersjo (1978) studied varying compliance of roller bearings and found that it arises because of variation of the number of rolling elements carrying

*Corresponding author. Tel.: (618) 453-7002. Fax: (618) 453-7658. E-mail: farhang@siu.edu. 
an external load. Bal'mont et al. (1987) attributed two factors to structural vibrations in bearings: (a) bending vibration of the outer race due to contact force of the balls and (b) variable rigidity of the rotating ball bearing under the action of the radial load component. In their analysis, radial thrust ball bearings were considered. The fluctuation of rigidity was found to occur when the rolling elements moved relative to the line of action of the radial load. The rigidity was determined to vary periodically at frequencies which are multiples of the ball rotational frequency.

Tallian and Gustafsson (1965) studied a model of rolling element bearings that described the associated frequency spectrum and amplitude relationships. They attributed two factors to the vibration of the outer ring: (1) cyclic variations in the compliance of the bearing and (2) geometric imperfections of the bearing. On examining the geometric imperfections, the authors found that the balls were the most important influencing elements followed by the inner and the outer rings.

Rahnejat and Gohar (1985) considered a rolling element bearing together with the oil film, as nonlinear springs and dampers are rotating about a spindle. When a periodic or step load was applied, squeeze films were developed in addition to the films created by normal rolling motion. The variation of pressure (load) with film thickness and squeeze speed was studied. The authors found that rotating unbalance and surface features introduce further significant frequencies which influence the response. Under the weight of the shaft, the frequency observed was a limit cycle. The frequency and amplitude were affected by the number of balls, applied load and radial internal clearance.

In the existing literature on vibration in rolling element bearings, contacts between the rolling elements and the inner and outer races have been considered in order to establish a combined (resultant) bearing stiffness. As a result, the interactions between the individual rolling elements and the rings have not been taken into consideration. The present work addresses such interactions by developing a model to account for the structural vibra- tions in rolling element bearings. Each element is treated separately taking into account its interaction with the other elements. The equation for Hertzian contact deformation has been used to develop the nonlinear contact stiffness. An approach based on the equivalence between journal and rolling bearings have been used to establish equivalent damping coefficients due to the presence of lubricants.

\section{THE GOVERNING EQUATIONS}

Figure 1(a) illustrates the model of the rolling element bearing. The contact stiffness between the $i$ th ball and inner and outer races are represented, respectively, by springs $K_{1 i}$ and $K_{2 i}$. The cage ensures constant angular separation between the adjacent rolling elements (Datta, 1991; Datta and Farhang, 1997a,b). Therefore, the azimuth angle of rolling element $i(i=2,3, \ldots, N)$ is related to that of

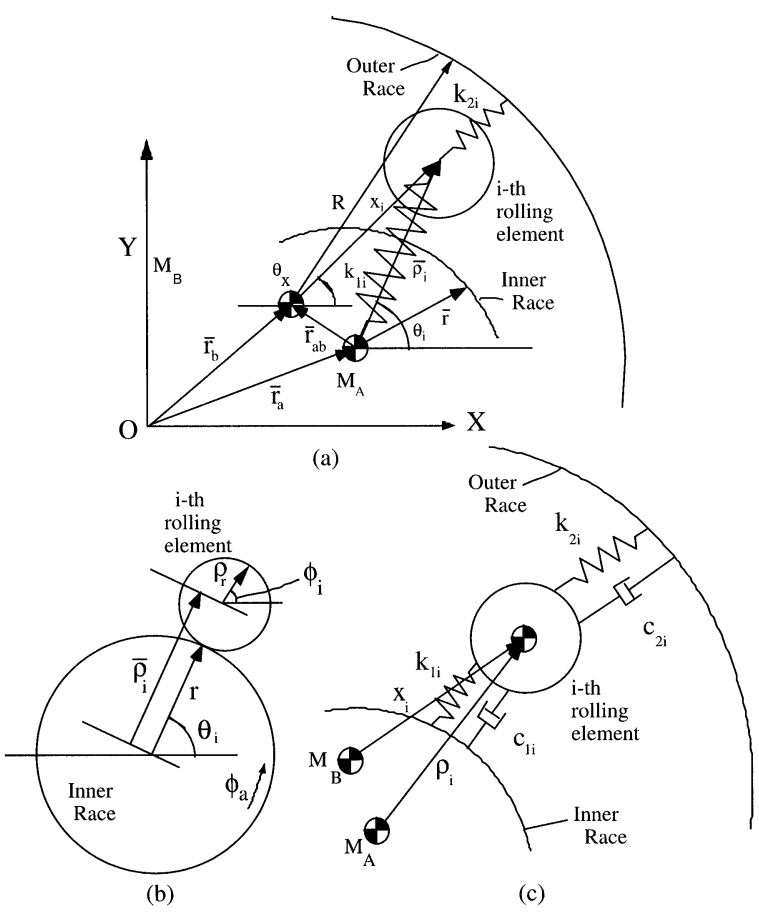

FIGURE 1 Schematic drawing of the rolling element bearing. 
the first as follows:

$$
\theta_{i}=\theta_{1}+(i-1) \beta, \quad i=1,2, \ldots, N,
$$

where, the constant angular separation is given by $\beta=2 \pi / N$.

The equations of motion for the bearing system are obtained using the Lagrange's equation for a set of independent generalized coordinates

$$
\frac{\mathrm{d}}{\mathrm{d} t}\left(\frac{\partial T}{\partial \dot{q}_{k}}\right)-\frac{\partial T}{\partial q_{k}}+\frac{\partial V}{\partial q_{k}}+\frac{\partial P_{\mathrm{f}}}{\partial \dot{q}_{k}}=Q_{k},
$$

where $q_{k}$ and $Q_{k}$ are, respectively, the $k$-th generalized coordinate and the corresponding generalized force. The total kinetic energy $(T)$, and the potential energy $(V)$ of the bearing system are the sum of those of the rolling elements, the inner and outer rings, and the cage. $P_{\mathrm{f}}$ represents the dissipation energy due to lubrication.

The total kinetic energy $(T)$ of the bearing may be expressed as

$$
T=T_{\text {r.e. }}+T_{\text {i.r. }}+T_{\text {o.r. }}+T_{\mathrm{c}}
$$

where $T_{\text {r.e. }}$ represent the kinetic energy sum of the rolling elements. $T_{\text {i.r. }}, T_{\text {o.r. }}$ and $T_{\mathrm{c}}$ denote the kinetic energies of the inner and outer rings and the cage, respectively. Neglecting slip, the rolling contact equation for the $i$ th rolling element and the inner ring (Fig. 1(b)) can be written as

$$
\rho_{r}\left(\dot{\phi}_{i}-\dot{\theta}_{i}\right)=-r\left(\dot{\phi}_{\mathrm{a}}-\dot{\theta}_{i}\right) .
$$

Hence,

$$
\dot{\phi}_{i}=\dot{\theta}_{i}-\frac{r}{\rho_{r}}\left(\dot{\phi}_{\mathrm{a}}-\dot{\theta}_{i}\right)
$$

where $\phi_{i}$ denotes the rotation of the $i$ th rolling element about its center of mass. Similarly, considering the rolling contact equation between the $i$ th rolling element and the outer ring,

$$
\dot{\phi}_{\mathrm{b}}=\dot{\theta}_{i}\left(1+\frac{r}{R}\right)-\frac{r}{R} \dot{\phi}_{\mathrm{a}} .
$$

Referring to Fig. 1(b), the kinetic energy of the $i$ th rolling element is expressed as

$$
\begin{aligned}
T_{i}= & \frac{1}{2} m_{i}\left[\dot{\rho}_{i}^{2}+\rho_{i}^{2} \dot{\theta}_{i}^{2}+\dot{x}_{\mathrm{a}}^{2}+2 \dot{x}_{\mathrm{a}} \dot{\rho}_{i} \cos \theta_{i}\right. \\
& -2 \dot{x}_{\mathrm{a}} \rho_{i} \dot{\theta}_{i} \sin \theta_{i}+\dot{y}_{\mathrm{a}}^{2}+2 \dot{y}_{\mathrm{a}} \dot{\rho}_{i} \sin \theta_{i} \\
& \left.+2 \dot{y}_{\mathrm{a}} \rho_{i} \dot{\theta}_{i} \cos \theta_{i}\right]+\frac{1}{2} I_{i}\left[\dot{\theta}_{i}-\frac{r}{\rho_{r}}\left(\dot{\phi}_{\mathrm{a}}-\dot{\theta}_{i}\right)\right]^{2} .
\end{aligned}
$$

The kinetic energy expressions for the inner and the outer rings are

$$
\begin{gathered}
T_{\text {i.r. }}=\frac{1}{2} m_{\mathrm{a}}\left(\dot{x}_{\mathrm{a}}^{2}+\dot{y}_{\mathrm{a}}^{2}\right)+\frac{1}{2} I_{\mathrm{a}} \dot{\phi}_{\mathrm{a}}^{2}, \\
T_{\text {o.r. }}=\frac{1}{2} m_{\mathrm{b}}\left(\dot{\overline{r_{\mathrm{b}}}} \cdot \dot{\overline{r_{\mathrm{b}}}}\right)+\frac{1}{2} I_{\mathrm{b}} \dot{\phi}_{\mathrm{b}}^{2} \\
=\frac{1}{2} m_{\mathrm{b}}\left[\left(\dot{x}_{\mathrm{b}}\right)^{2}+\left(\dot{y}_{\mathrm{b}}\right)^{2}\right]+\frac{1}{2} I_{\mathrm{b}} \dot{\phi}_{\mathrm{b}}^{2} .
\end{gathered}
$$

The kinetic energy of the cage is calculated by assuming that its center remains coincident with that of the inner ring. Therefore,

$$
T_{\mathrm{c}}=\frac{1}{2} m_{\mathrm{c}}\left(\dot{x}_{\mathrm{a}}^{2}+\dot{y}_{\mathrm{a}}^{2}\right)+\frac{1}{2} I_{\mathrm{c}} \dot{\theta}_{\mathrm{i}}^{2} .
$$

The potential energy formulation is performed taking datum as the horizontal plane through the global origin. The total potential energy of the bearing is

$$
V=V_{\text {r.e. }}+V_{\text {i.r. }}+V_{\text {o.r. }}+V_{\mathrm{s}}+V_{\mathrm{c}},
$$

where $V_{\text {r.e., }}, V_{\text {i.r. }}, V_{\text {o.r. }}, V_{\mathrm{s}}$ and $V_{\mathrm{c}}$ are the potential energies due to elevation of the rolling elements, inner and outer rings, springs, and the cage, respectively. For the rolling elements, the potential energy due to elevation is given by

$$
\begin{aligned}
V_{\text {r.e. }} & =\sum_{i=1}^{N} m_{i} g\left(\rho_{i} \sin \theta_{i}+y_{\mathrm{a}}\right) \\
& =m g N y_{\mathrm{a}}+\sum_{i=1}^{\mathrm{N}}\left(m_{i} \rho_{i} g \sin \theta_{i}\right) .
\end{aligned}
$$

For the inner and the outer rings,

$$
V_{\text {i.r. }}=m_{\mathrm{a}} g y_{\mathrm{a}},
$$

$$
V_{\text {o.r. }}=m_{\mathrm{b}} g y_{\mathrm{b}}
$$


The deformation of the springs $k_{1 i}$ and $k_{2 i}$ are $\left(\rho_{i}-L_{10}\right)$ and $\left(R-x_{i}-L_{20}\right)$, respectively. The expression for the potential energy due to the contact deformation is, therefore,

$$
\begin{aligned}
V_{\mathrm{s}}= & \sum_{i=1}^{N} \frac{1}{2} k_{1 i}\left(\rho_{i}-L_{10}\right)^{2} \\
& +\sum_{i=1}^{N} \frac{1}{2} k_{2 i}\left(R-x_{i}-L_{20}\right)^{2},
\end{aligned}
$$

where $k_{1 i}$ and $k_{2 i}$ are the nonlinear stiffnesses due to Hertzian contact between the ball and the inner and outer races, respectively. The potential energy due to the cage elevation is

$$
V_{\mathrm{c}}=m_{\mathrm{c}} g y_{\mathrm{a}} .
$$

Energy dissipation in the bearing may be expressed as

$$
P_{\mathrm{f}}=\frac{1}{2} \sum_{i=1}^{N}\left(c_{1 i} \dot{\rho}_{i}^{2}+\frac{1}{2} c_{2 i} \dot{x}_{i}^{2}\right) .
$$

The equations of motion for the bearing are obtained using Eqs. (2)-(16).

Employing Lagrange's equation, and assuming that the motion of the inner ring is known, the governing equations of motion for the generalized coordinates $\rho_{i}(i=1,2, \ldots, N)$ are obtained

$$
\begin{aligned}
& m_{i} \ddot{\rho}_{i}+m_{i} g \sin \theta_{i}+m_{i} \rho_{i} \dot{\theta}^{2}+k_{1 i}\left(\rho_{i}-L_{10}\right) \\
& -k_{2 i}\left(R-x_{i}-L_{20}\right) \frac{\partial x_{i}}{\partial \rho_{i}}+m_{i} \ddot{x}_{\mathrm{a}} \cos \theta_{i}+m_{i} \ddot{y}_{\mathrm{a}} \sin \theta_{i} \\
& +\frac{1}{2} \frac{\partial k_{1 i}}{\partial \rho_{i}}\left(\rho_{i}-L_{10}\right)^{2}+\frac{1}{2} \frac{\partial k_{2 i}}{\partial \rho_{i}}\left(R-x_{i}-L_{20}\right)^{2}+c_{1 i} \dot{\rho}_{i} \\
& +c_{2 i} \dot{x}_{i} \frac{\partial \dot{x}_{i}}{\partial \dot{\rho}_{i}}=0 ; \quad i=1,2, \ldots, N .
\end{aligned}
$$

The equations of motion for the generalized coordinates $x_{\mathrm{b}}$ and $y_{\mathrm{b}}$ are

$$
\begin{gathered}
m_{\mathrm{b}} \ddot{x}_{\mathrm{b}}-\sum_{i=1}^{N} k_{2 i}\left(R-x_{i}-L_{20}\right) \frac{\partial x_{i}}{\partial x_{\mathrm{b}}} \\
+\sum_{i=1}^{N} c_{2 i} \dot{x}_{i} \frac{\partial \dot{x}_{i}}{\partial \dot{x}_{\mathrm{b}}}=F_{x},
\end{gathered}
$$

$$
\begin{gathered}
m_{\mathrm{b}} \ddot{y}_{\mathrm{b}}+m_{\mathrm{b}} g-\sum_{i=1}^{N} k_{2 i}\left(R-x_{i}-L_{20}\right) \frac{\partial x_{i}}{\partial y_{\mathrm{b}}} \\
+\sum_{i=1}^{N} c_{2 i} \dot{x}_{i} \frac{\partial \dot{x}_{i}}{\partial \dot{y}_{\mathrm{b}}}=F_{y},
\end{gathered}
$$

where $F_{x}$ and $F_{y}$ are the generalized forces on the outer ring of the bearing, corresponding to the generalized coordinates $x_{\mathrm{b}}$ and $y_{\mathrm{b}}$, respectively. When the motion of the inner ring is known, Eqs. (17)-(19) can be solved to obtain the radial displacement of each ball, and the $x$ and $y$ displace ments of the outer ring center. This is a system of $N+2$ second-order, nonlinear, ordinary differential equations with time-dependent coefficients. The reader may refer to Appendix A for details on equivalent spring constants, $k_{1 i}$ and $k_{2 i}, x_{i}$ and its derivatives.

The equations of motion may be normalized with respect to the physical and geometrical properties of the rolling elements, i.e. average mass and radius,

$$
m_{1}=m_{2}=\cdots=m_{\mathrm{av}}, \quad \rho_{r_{1}}=\rho_{r_{2}}=\cdots=\rho_{r_{\mathrm{av}}},
$$

where $m_{\mathrm{av}}$ and $\rho_{\mathrm{av}}$ represent the average values. After some manipulations, the normalized equations of motion in terms of the normalized parameters are

$$
\begin{aligned}
\ddot{\rho}_{i}^{*} & +g^{*} \sin \theta_{i}-\rho_{i}^{*} \dot{\theta}_{i}^{2}+k_{1 i}^{*}\left(\rho_{i}^{*}-L_{10}^{*}\right) \\
& -k_{2 i}^{*}\left(R^{*}-x_{i}^{*}-L_{20}^{*}\right) \frac{\partial x_{i}^{*}}{\partial \rho_{i}^{*}} \\
& +\ddot{x}_{\mathrm{a}}^{*} \cos \theta_{i}+\ddot{y}_{\mathrm{a}}^{*} \sin \theta_{i} \\
& +\frac{1}{2} \frac{\partial k_{1 i}^{*}}{\partial \rho_{i}^{*}}\left(\rho_{i}^{*}-L_{10}^{*}\right)^{2}+\frac{1}{2} \frac{\partial k_{2 i}^{*}}{\partial \rho_{i}^{*}}\left(R^{*}-x_{i}^{*}-L_{20}^{*}\right)^{2} \\
& +c_{1 i}^{*} \dot{\rho}_{i}^{*}+c_{2 i}^{*} \dot{x}_{i}^{*} \frac{\partial \dot{x}_{i}^{*}}{\partial \dot{\rho}_{i}^{*}}=0
\end{aligned}
$$

$$
\begin{gathered}
m_{\mathrm{b}}^{*} \ddot{x}_{\mathrm{b}}^{*}-\sum_{i=1}^{N} k_{2 i}^{*}\left(R^{*}-x_{i}^{*}-L_{20}^{*}\right) \frac{\partial x_{i}^{*}}{\partial x_{\mathrm{b}}^{*}} \\
+\sum_{i=1}^{N} c_{2 i}^{*} \dot{x}_{i}^{*} \frac{\partial \dot{x}_{i}^{*}}{\partial \dot{x}_{\mathrm{b}}^{*}}=F_{x}^{*},
\end{gathered}
$$




$$
\begin{aligned}
& m_{\mathrm{b}}^{*} \ddot{y}_{\mathrm{b}}^{*}+m_{\mathrm{b}}^{*} g^{*}-\sum_{i=1}^{N} k_{2 i}^{*}\left(R^{*}-x_{i}^{*}-L_{20}^{*}\right) \frac{\partial x_{i}^{*}}{\partial y_{\mathrm{b}}^{*}} \\
& +\sum_{i=1}^{N} c_{2 i}^{*} \dot{x}_{i}^{*} \frac{\partial \dot{x}_{i}^{*}}{\partial \dot{y}_{\mathrm{b}}^{*}}=F_{y}^{*} .
\end{aligned}
$$

\section{RESULTS}

Equations (20)-(22) are utilized to predict the motion of each ball and the outer ring. In the ensuing sections, vibration response of a ball (hereafter referred to as ball 1), initially located at the zero azimuth angle is presented. In addition, outer ring motion is presented as displacements of its center of mass along the global coordinate axes, $X$ and $Y$.

\section{Effect of Preload}

The vibration responses of ball 1 and the outer ring in the presence of a preload of 10 and $1 \mathrm{~N}$ are shown in Fig. 2. Comparison of the figures suggests that the frequency of oscillation increases in the presence of preload. This is due to the increased stiffness of the bearing. In the absence of preload, the response amplitude of vibra-tion of ball 1 is almost three times larger than that in the presence of preload. Also, the outer ring center shows amplitudes that are almost an order of magnitude larger than those in the presence of preload.

When the preload is reduced from 10 to $1 \mathrm{~N}$, no significant change is observed in the motions of ball 1 and the outer ring center (Fig. 2). The frequency remains almost the same and the amplitude in the case of $1 \mathrm{~N}$ preload increases very slightly, as expected.

\section{Effect of Interference Check}

The springs representing the Hertzian contact are allowed to act only in compression, and to ensure this, the interference checks are performed. In the

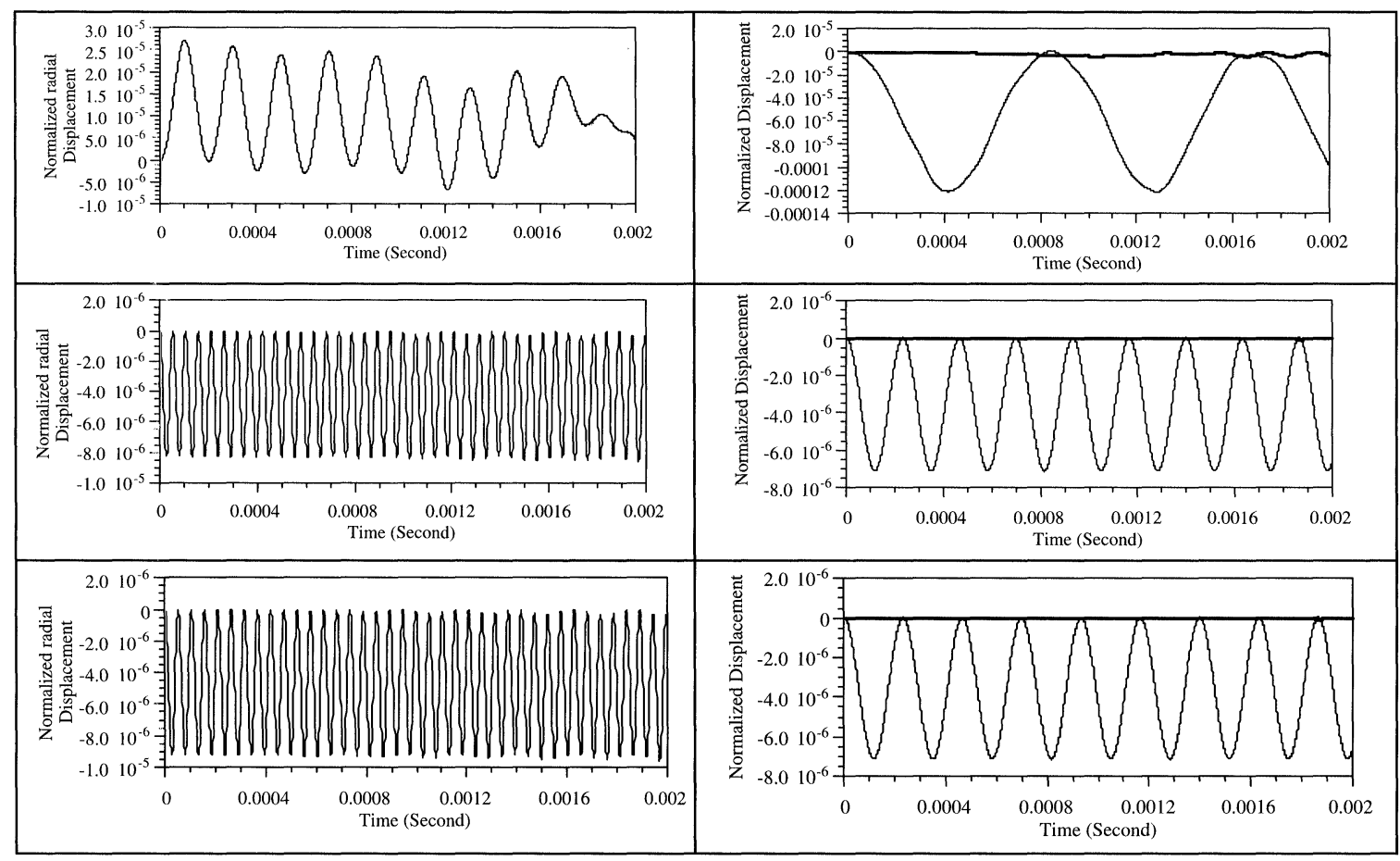

FIGURE 2 Normalized radial displacement of ball 1 and the $x$ and $y$ displacement of outer ring center - interference checked: Left column is ball motion, right column is outer ring motion, top row corresponds to no preload, middle row preload of $10 \mathrm{~N}$ and bottom row preload of $1 \mathrm{~N}$ ( $-x$-displacement, $-y$-displacement). 
absence of preload, responses of ball 1 are observed for the cases in which interference checks are performed (Fig. 2) and are neglected (Fig. 3). The frequency and amplitudes of oscillation are quite different in the two cases. In contrast, a comparison of the same cases in the presence of preload, Fig. 2 with Fig. 3, illustrates strong agreement between the corresponding responses. The preload seems to ensure the ball-race contact, thereby making the interference checks unnecessary. This effect is of special significance since in practice, bearings are expected to have some amount of preload after assembly.

\section{Effect of Ball Rotational Speed}

Figure 4 shows the state of contact when the bearing is run at an extremely high speed of rotation. It is assumed that there is no preload, and the ball rotational speed is 74,990 RPM.
Figure 4(a) illustrates the state of contact between the eight balls and the inner race, whereas Fig. 4(b) shows the corresponding contact conditions between the eight balls and the outer race. In the aforementioned figures, each ball is assigned two states indicated by odd and even numbers. Odd numbers on the ordinate indicate a no-contact condition, while even numbers represent a state of contact. Since there are 8 balls in bearing 6204, there are 16 numbers in all. For example, numbers 1 and 2 are associated with ball 1, numbers 3 and 4 with ball 2, and so on. A plotted line corresponding to a state signifies the existence of that state.

Figure 4(a) shows that at almost all time instants, the dark band appears for an odd number on the $y$ axis, indicating that there is no contact between the balls and the inner race. The dark band appears momentarily against an even number, signifying that all the balls have contact with the inner race for

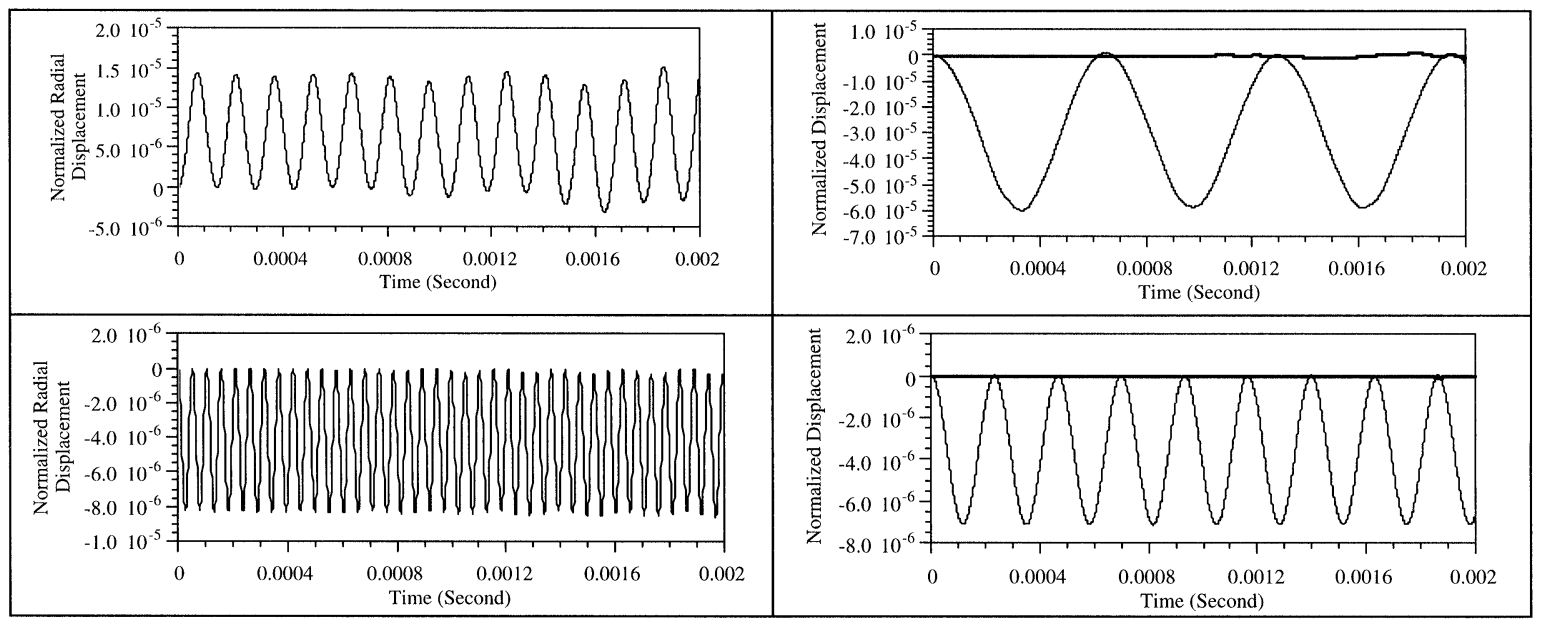

FIGURE 3 Normalized radial displacement of ball 1 and the $x$ and $y$ displacement of outer ring center - interference checked: Left column is ball motion, right column is outer ring motion, top row corresponds to no preload, and bottom row preload of $10 \mathrm{~N}$ ( $-x$-displacement, $-y$-displacement).

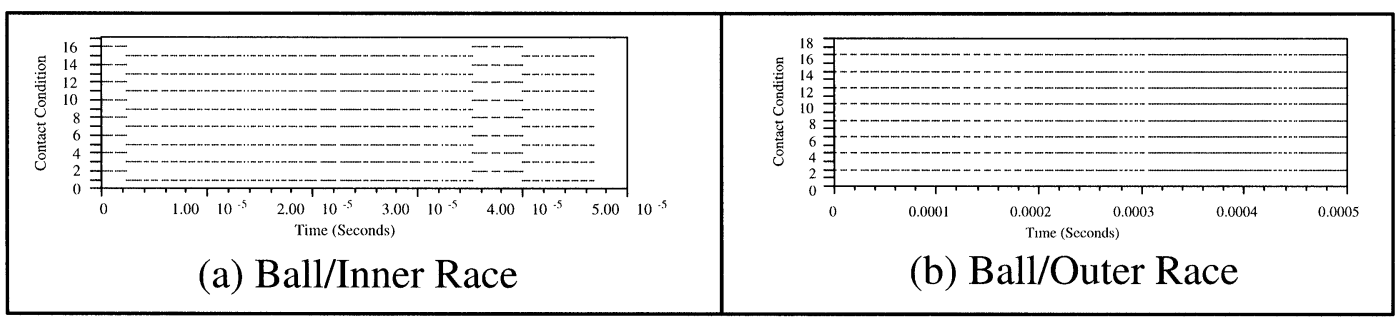

FIGURE 4 Ball/race contact. 
a very brief duration of time. On the other hand, Fig. 4(b) shows the dark band for all even numbers on the ordinate, indicating contact between the balls and the outer race at all times. This phenomenon is primarily due to the presence of high centrifugal forces on the balls, causing the balls to experience a radially outward thrust, thus maintaining contact with the outer race.

\section{Effect of Fluid Film Lubrication}

Damping corresponding to a film thickness equal to $10^{-3} \mathrm{~mm}$, and a dynamic oil viscosity of $3.4 \times$ $10^{-2} \mathrm{~kg} / \mathrm{ms}$ is introduced in the mathematical model. The damping coefficients $c_{1 i}^{*}$ and $c_{2 i}^{*}$ are estimated using Eqs. (A.16) and (A.17) and refer- ring to the relevant constants in Table I and Eschmann et al. (1985).

Figures 5 depict the vibration response of ball 1 . It is seen that the transient vibrations decay, and a vibration response of smaller frequency and magnitude persists. Although the ball oscillation is dampened considerably, it is periodic in nature and repeats after almost one cycle of rotation. The motion of the outer ring center exhibits decay in vibrations. The $x$ and the $y$ displacements show a steady-state behavior after nearly $50^{\circ}$ of rotation of the outer ring. The negative value of the average amplitude of oscillations (in the $y$ direction) of the outer ring is attributed to the effect of the gravitational term appearing in the governing equation of motion, Eq. (22).

TABLE I Geometric and physical parameters of ball bearing 6204

\begin{tabular}{|c|c|c|c|}
\hline \multicolumn{4}{|l|}{ Outside diameter } \\
\hline Ball mass $(m)$ & $0.002 \mathrm{~kg}$ & Mass of each ball $(m)$ & 1.0 \\
\hline Number of balls $(N)$ & 8 & Radius of the ball $\left(\rho_{r}\right)$ & 1.0 \\
\hline Total ball mass $(m N)$ & $0.0160 \mathrm{~kg}$ & $\begin{array}{l}\text { Undeformed length } \\
\text { of spring } 1\left(L_{10}\right)\end{array}$ & 4.2671 \\
\hline Inner ring mass $\left(m_{\mathrm{a}}\right)$ & $0.0297 \mathrm{~kg}$ & $\begin{array}{l}\text { Undeformed length } \\
\text { of spring } 2\left(L_{10}\right)\end{array}$ & 0.9188 \\
\hline Outer ring mass $\left(m_{\mathrm{b}}\right)$ & $0.0497 \mathrm{~kg}$ & Mass of inner ring $\left(m_{\mathrm{a}}\right)$ & 14.85 \\
\hline Cage mass $\left(m_{\mathrm{c}}\right)$ & $0.0048 \mathrm{~kg}$ & Mass of outer ring $\left(m_{\mathrm{b}}\right)$ & 24.85 \\
\hline $\begin{array}{l}\text { Total mass of rings, } \\
\text { balls and cage }\end{array}$ & $0.1002 \mathrm{~kg}$ & Mass of cage $\left(m_{\mathrm{c}}\right)$ & 2.40 \\
\hline Radius ( $r$ ) of inner ring & $13.3527 \mathrm{~mm}$ & Radius $(r)$ of inner ring & 3.3483 \\
\hline Radius $(R)$ of outer ring & $20.6806 \mathrm{~mm}$ & Radius $(R)$ of outer ring & 5.1859 \\
\hline Radius of the ball $\left(\rho_{r}\right)$ & $3.9878 \mathrm{~mm}$ & $\begin{array}{l}\text { Radial position } \\
\text { of the } i \text { th ball }\left(\rho_{i}\right)\end{array}$ & 4.2671 \\
\hline $\begin{array}{l}\text { Ball moment } \\
\text { of inertia }(I)\end{array}$ & $5.0 \times 10^{-7} \mathrm{~kg} \mathrm{~m}^{2}$ & $\begin{array}{l}\text { Moment of inertia } \\
\text { of the ball }(I)\end{array}$ & 0.5 \\
\hline $\begin{array}{l}\text { Moment of inertia } \\
\text { of inner ring }\left(I_{\mathrm{a}}\right)\end{array}$ & $1.45 \times 10^{-5} \mathrm{~kg} \mathrm{~m}^{2}$ & $\begin{array}{l}\text { Moment of inertia } \\
\text { of inner ring }\left(I_{\mathrm{a}}\right)\end{array}$ & 455.0 \\
\hline $\begin{array}{l}\text { Moment of inertia } \\
\text { of outer ring }\left(I_{\mathrm{b}}\right)\end{array}$ & $6.91 \times 10^{-6} \mathrm{~kg} \mathrm{~m}^{2}$ & $\begin{array}{l}\text { Moment of inertia } \\
\text { of outer ring }\left(I_{\mathrm{b}}\right)\end{array}$ & 217.0 \\
\hline $\begin{array}{l}\text { Moment of inertia } \\
\text { of the cage }\left(I_{\mathrm{c}}\right)\end{array}$ & $1.45 \times 10^{-6} \mathrm{~kg} \mathrm{~m}^{2}$ & $\begin{array}{l}\text { Moment of inertia } \\
\text { of the cage }\left(I_{\mathrm{c}}\right)\end{array}$ & 45.5 \\
\hline $\begin{array}{l}\text { Angular separation } \\
\text { of the balls }(\beta=2 \pi / N)\end{array}$ & $45^{\circ}$ & $\begin{array}{l}\text { Acceleration due } \\
\text { to gravity }(g)\end{array}$ & 2460 \\
\hline $\begin{array}{l}\text { Undeformed length } \\
\text { of spring } 1\left(L_{10}=(R+r) / 2\right)\end{array}$ & $17.0166 \mathrm{~mm}$ & $\begin{array}{l}\text { Normalized spring } \\
\text { constant } K_{1}(\mathrm{~N} / \mathrm{mm})\end{array}$ & $2.32 \times 10^{11} \times \sqrt{\rho_{i}-L_{10}}$ \\
\hline \multirow[t]{5}{*}{$\begin{array}{l}\text { Undeformed length } \\
\text { of spring } 2\left(L_{20}=R-L_{10}\right)\end{array}$} & $3.6640 \mathrm{~mm}$ & $\begin{array}{l}\text { Normalized spring } \\
\text { constant } K_{2}(\mathrm{~N} / \mathrm{mm})\end{array}$ & $2.373 \times 10^{11} \times \sqrt{\rho_{i}-L_{10}}$ \\
\hline & & Normalized $\mathrm{d} k_{1 i} / \mathrm{d} \rho_{i}$ & $1.160 \times 10^{11} \times\left(\rho_{i}-L_{10}\right)^{-0.5}$ \\
\hline & & Normalized $\mathrm{d} k_{2 i} / \mathrm{d} \rho_{i}$ & $-1.1865 \times 10^{11} \times\left(\rho_{i}-X_{i}-L_{10}\right)^{-0.5} \times\left(\mathrm{d} X_{i} / d \rho_{i}\right)$ \\
\hline & & $\begin{array}{l}\text { Normalized force in the } \\
X \text { direction (Newtons) }\end{array}$ & 0.0 \\
\hline & & $\begin{array}{l}\text { Normalized force in the } \\
Y \text { direction (Newtons) }\end{array}$ & 0.0 \\
\hline
\end{tabular}




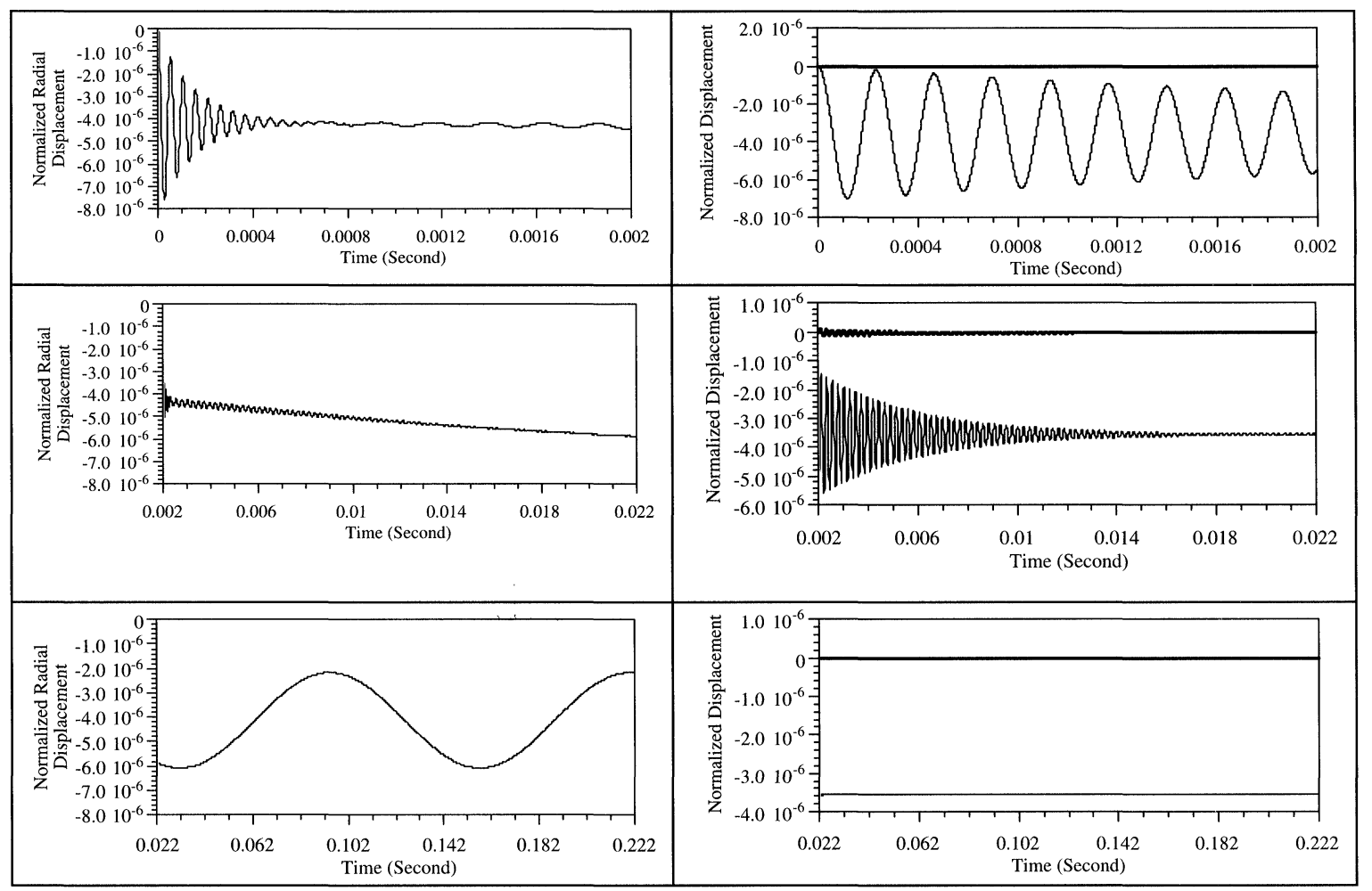

FIGURE 5 Normalized radial displacement of ball 1 and the $x$ and $y$ displacement of the outer ring: Left column is ball motion, right column is outer ring motion (viscosity $=0.034 \mathrm{~kg} / \mathrm{m} \mathrm{s})(-x$-displacement, $-y$-displacement).

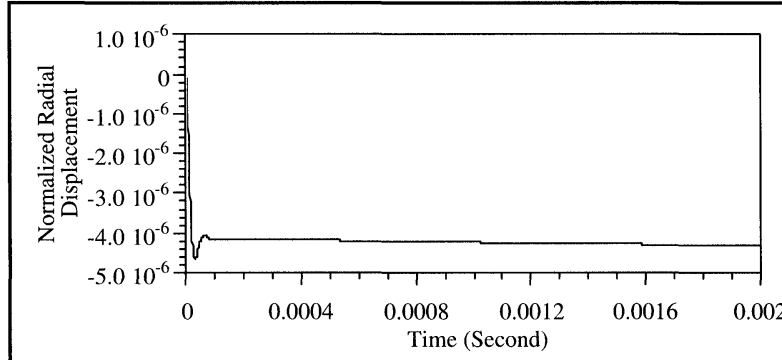

(a) Normalized Radial Displacement of Ball 1

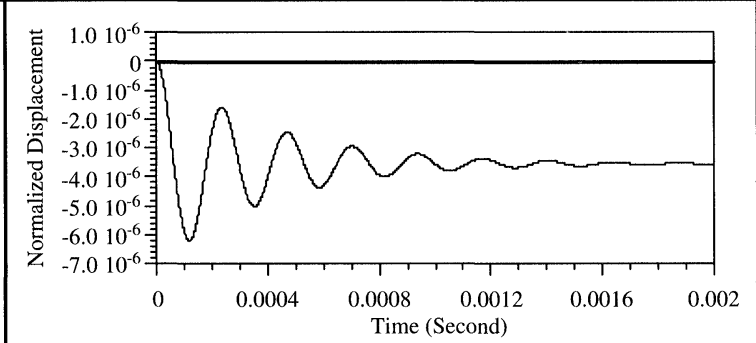

(b) Motion of the Outer Ring Center

FIGURE 6 Bearing vibration (viscosity $=0.34 \mathrm{~kg} / \mathrm{m} \mathrm{s})(-x$-displacement, $-y$-displacement).

When the damping is increased by an order of magnitude, there is hardly any oscillation in the motion of ball 1, as shown in Fig. 6. Similarly, there is a rapid decay in the oscillations of the outer ring center, as depicted in Fig. 6. Thus, introduction of fluid film lubrication helps in dampening the oscillations to a large extent.

\section{CONCLUSIONS}

A lumped parameter model has been introduced in this paper to investigate structural vibrations in ball bearings. Using the model, effects of preload, operational speed, and fluid film damping on the vibration response of the bearing have been 
studied. The foregoing results provide the following conclusions:

The presence of preload results in oscillations of relatively higher frequency and at comparatively lower amplitudes. Furthermore, the vibration response is found to be highly sensitive to the mere existence of preload and not as much to its amount, as preloads of $100-1 \mathrm{~N}$ do not cause appreciable difference in the response. So long as there exists preload in the bearing, the interference check has little influence on the vibration response. In contrast, in the absence of preload, the interference checks have a profound influence on the response. A significant implication of this is reflected in the linearization of the equations of motion: preload facilitates linear model representation of a rolling element bearing.

When the bearing is run at an extremely high ball rotational speed, contact between the balls and the outer race is maintained, while there is intermittent contact of the balls with the inner race for very brief periods of time.

Introduction of a lubricant is found to dampen the oscillations considerably. For higher lubricant viscosity, the oscillations exhibit an almost steadystate behavior after a short time interval. With an increase in lubricant viscosity, the decay is observed to be quite rapid.

\section{Acknowledgments}

The authors acknowledge the Office of Research Development and Administration (ORDA) of Southern Illinois University at Carbondale, for providing financial assistance to the first author during this work.

\section{NOMENCLATURE}

$\begin{array}{ll}b_{\mathrm{ss}} & \text { damping coefficient } \\ c & \text { radial clearance } \\ c_{1 i} & \begin{array}{l}\text { coefficient of damping between the } \\ \text { inner race and the } i \text { th element }\end{array} \\ c_{2 i} & \begin{array}{l}\text { coefficient of damping between the } \\ \text { outer race and the } i \text { th element }\end{array}\end{array}$

\section{$r$}

$R$

$\bar{r}_{\mathrm{a}}$

$\bar{r}_{\mathrm{b}}$

$\bar{r}_{\mathrm{ab}}$

$T$

V

$x_{i}$

$x_{\mathrm{a}}, \dot{x}_{\mathrm{a}}, \ddot{x}_{\mathrm{a}}$ contact deformation in Hertz equation Young's modulus of elasticity acceleration due to gravity stiffness of spring 1 between inner race and the $i$-th element

stiffness of spring 2 between outer race and the $i$ th element

coefficient in Hertz equation for deformation in point contact

length or the major axis of the elliptical contact region

undeformed length of spring 1 (length at equilibrium) - ball/inner race contact undeformed length of spring 2 (length at equilibrium) - ball/outer race contact

Poisson ratio

mass of the inner ring

mass of the outer ring

inner ring center of mass

outer ring center of mass

number of rolling elements in the bearing

oil viscosity

dissipation energy term in the Lagrange equation

$k$ th generalized coordinate in the Lagrange equation

generalized force in the Lagrange equation

external radius of inner ring internal radius of outer ring position vector of the inner ring center of mass

position vector of the outer ring center of mass

position vector of the outer ring center of mass with respect to the inner ring center of mass

total kinetic energy of the bearing total potential energy of the bearing vector magnitude defining length of spring 2

$x$-displacement, velocity, and acceleration of the inner ring center of mass 
$y_{\mathrm{a}}, \dot{y}_{\mathrm{a}}, \ddot{y}_{\mathrm{a}} \quad y$-displacement, velocity, and acceleration of the inner ring center of mass

$x_{\mathrm{b}}, \dot{x}_{\mathrm{b}}, \ddot{x}_{\mathrm{b}} \quad \mathrm{x}$-displacement, velocity, and acceleration of the outer ring center of mass

$y_{\mathrm{b}}, \dot{y}_{\mathrm{b}}, \ddot{y}_{\mathrm{b}} \quad y$-displacement, velocity, and acceleration of the outer ring center of mass

$\mu \quad$ coefficient in Hertz equation for deformation in point contact

$\phi_{i} \quad$ spin displacement of the $i$ th rolling element

$\phi_{\mathrm{a}}, \dot{\phi}_{\mathrm{a}} \quad$ angular displacement and velocity of the inner ring

$\theta_{i}, \dot{\theta}_{i} \quad$ angular displacement and velocity of the cage

$\theta_{x} \quad$ orientation of spring 2 , representing contact stiffness between the ball and the outer ring

$\rho_{i}, \dot{\rho}_{i} \quad$ radial position and velocity of the $i$ th rolling element

\section{APPENDIX A}

To quantify the deformation of spring $2, x_{i}$ is defined as shown in Fig. 1(a). Considering this figure,

$$
\begin{aligned}
& x_{i} \cos \theta_{x}+x_{\mathrm{b}}=\rho_{i} \cos \theta_{i}+x_{\mathrm{a}}, \\
& x_{i} \sin \theta_{x}+y_{\mathrm{b}}=\rho_{i} \sin \theta_{i}+y_{\mathrm{a}} .
\end{aligned}
$$

Solving for $x_{i}$,

$$
x_{i}=\left[\left(\rho_{i} \cos \theta_{i}+x_{\mathrm{a}}-x_{\mathrm{b}}\right)^{2}+\left(\rho_{i} \sin \theta_{i}+y_{\mathrm{a}}-y_{\mathrm{b}}\right)^{2}\right]^{1 / 2} .
$$

Equation (A.1) is used to obtain the partial derivatives of $x_{i}$ with respect to $\rho_{i}, x_{\mathrm{b}}$ and $y_{\mathrm{b}}$, which occur in the equations of motion. These partial derivatives are

$\frac{\partial x_{i}}{\partial \rho_{i}}=\frac{\rho_{i}+x_{\mathrm{a}} \cos \theta_{i}-x_{\mathrm{b}} \cos \theta_{i}+y_{\mathrm{a}} \sin \theta_{i}-y_{\mathrm{b}} \sin \theta_{i}}{x_{i}}$.

Similarly,

$$
\begin{aligned}
\frac{\partial x_{i}}{\partial x_{\mathrm{b}}} & =\frac{2 x_{\mathrm{b}}-2 \rho_{i} \cos \theta_{i}-2 x_{\mathrm{a}}}{2 x_{i}} \\
& =\frac{x_{\mathrm{b}}-\rho_{i} \cos \theta_{i}-x_{\mathrm{a}}}{x_{i}}, \\
\frac{\partial x_{i}}{\partial y_{\mathrm{b}}} & =\frac{2 y_{\mathrm{b}}-2 \rho_{i} \sin \theta_{i}-2 y_{\mathrm{a}}}{2 x_{i}} \\
& =\frac{y_{\mathrm{b}}-\rho_{i} \sin \theta_{i}-y_{\mathrm{a}}}{x_{i}} .
\end{aligned}
$$

The contact stiffness is given by Hertz equations for elastic deformation, involving point contact between solid bodies,

$$
\delta=1.5 \frac{2 K}{\prod \mu} \sqrt[3]{\frac{\left(1-1 / m^{2}\right)^{2}}{E^{2}} \frac{\sum \rho}{3} Q^{2}} \quad(\mathrm{~mm})
$$

where $K$ and $\mu$ are Hertz coefficients which depend on surface curvatures. $E, 1 / m$ and $\sum \rho$ are the elastic modulus in $\mathrm{N} / \mathrm{mm}^{2}$, Poisson's ratio, and curvature 
sum (in $\mathrm{mm}^{-1}$ ) of the contacting bodies, respectively. From the above equation, we obtain

$$
Q=\frac{E}{1-1 / m^{2}} \sqrt{\frac{3 \delta}{\left(1.5(2 K) /\left(\prod \mu\right)\right)^{3} \sum \rho}} \delta
$$

The nonlinear stiffness associated with point contact is then given by

$$
k=\frac{E}{1-1 / m^{2}} \sqrt{\frac{3 \delta}{\left(1.5(2 K) /\left(\prod \mu\right)\right)^{3} \sum \rho}}(\mathrm{N} / \mathrm{mm}) .
$$

From Eq. (16),

$$
\frac{\partial P_{\mathrm{f}}}{\partial \dot{\rho}_{i}}=c_{1 i} \dot{\rho}_{i}+c_{2 i} \dot{x}_{i} \frac{\partial \dot{x}_{i}}{\partial \dot{\rho}_{i}} .
$$

Also, the derivatives of $P_{\mathrm{f}}$ with respect to $\dot{x}_{\mathrm{b}}$ and $\dot{y}_{\mathrm{b}}$ are

$$
\frac{\partial P_{\mathrm{f}}}{\partial \dot{x}_{\mathrm{b}}}=\frac{1}{2} \sum_{i=1}^{N} c_{2 i} 2 \dot{x}_{i} \frac{\partial \dot{x}_{i}}{\partial \dot{x}_{\mathrm{b}}}=\sum_{i=1}^{N} c_{2 i} \dot{x}_{i} \frac{\partial \dot{x}_{i}}{\partial \dot{x}_{\mathrm{b}}}
$$

and

$$
\frac{\partial P_{\mathrm{f}}}{\partial \dot{y}_{\mathrm{b}}}=\frac{1}{2} \sum_{i=1}^{N} c_{2 i} 2 \dot{x}_{i} \frac{\partial \dot{x}_{i}}{\partial \dot{y}_{\mathrm{b}}}=\sum_{i=1}^{N} c_{2 i} \dot{x}_{i} \frac{\partial \dot{x}_{i}}{\partial \dot{y}_{\mathrm{b}}}
$$

where

$$
\begin{gathered}
\dot{x}_{i}=\frac{M_{1}}{x_{i}}, \\
M_{1}=x_{\mathrm{a}} \dot{x}_{\mathrm{a}}-x_{\mathrm{a}} \dot{x}_{\mathrm{b}}-x_{\mathrm{b}} \dot{x}_{\mathrm{a}}+\dot{\rho}_{i} x_{\mathrm{a}} \cos \theta_{i} \\
-\rho_{i} \dot{x}_{\mathrm{a}} \cos \theta_{i}+\rho_{i} x_{\mathrm{a}} \dot{\theta}_{i} \sin \theta_{i}+y_{\mathrm{a}} \dot{y}_{\mathrm{a}} \\
-y_{\mathrm{a}} \dot{y}_{\mathrm{b}}-y_{\mathrm{b}} \dot{y}_{\mathrm{a}}+\dot{\rho}_{i} y_{\mathrm{a}} \cos \theta_{i}-\rho_{i} \dot{y}_{\mathrm{a}} \cos \theta_{i} \\
+\rho_{i} y_{\mathrm{a}} \theta_{i} \sin \theta_{i}+\rho_{i} \dot{\rho}_{i}+x_{\mathrm{b}} \dot{x}_{\mathrm{b}}-\dot{\rho}_{i} x_{\mathrm{b}} \cos \theta_{i} \\
-\rho_{i} \dot{x}_{\mathrm{b}} \cos \theta_{i}+\rho_{i} x_{\mathrm{b}} \dot{\theta}_{i} \sin \theta_{i}+y_{\mathrm{b}} \dot{y}_{\mathrm{b}} \\
-\dot{\rho}_{i} y_{\mathrm{b}} \sin \theta_{i}-\rho_{i} \dot{y}_{\mathrm{b}} \sin \theta_{i}+\rho_{i} y_{\mathrm{b}} \dot{\theta}_{i} \cos \theta_{i} .
\end{gathered}
$$

Other derivatives appearing in the equations of motion are

$\frac{\partial \dot{x}_{i}}{\partial \dot{\rho}_{i}}=\frac{\rho_{i}+x_{\mathrm{a}} \cos \theta_{i}+y_{\mathrm{a}} \sin \theta_{i}-x_{\mathrm{b}} \cos \theta_{i}-y_{\mathrm{b}} \sin \theta_{i}}{x_{i}}$

$$
\frac{\partial \dot{x}_{i}}{\partial \dot{x}_{\mathrm{b}}}=\frac{x_{\mathrm{b}}-\rho_{i} \cos \theta_{i}-x_{\mathrm{a}}}{x_{i}}
$$

$$
\frac{\partial \dot{x}_{i}}{\partial \dot{y}_{\mathrm{b}}}=\frac{y_{\mathrm{b}}-y_{\mathrm{a}}-\rho_{i} \sin \theta_{i}}{x_{i}} .
$$

To calculate the coefficients $c_{1 i}^{*}$ and $c_{2 i}^{*}$, an analogy is drawn from the expression of damping coefficient for short journal bearings as enunciated by Holmes et al. (1986). According to the authors, the lateral coefficient of damping for the ball bearing (having motion in the radial plane only) is given as

$$
b_{\mathrm{ss}}=\frac{\pi \eta R L^{3}}{c^{3}}
$$

In the case of ball bearings, $R$ (radius of the journal) will correspond to $\rho_{\mathrm{d}} / 2$ where $\rho_{\mathrm{d}}$ is the diameter of the ball. Also, $c$ (radial clearance) can be compared to the thickness of the lubricant ' $h h_{0}$ '. The expression for $L$ is given by Eschmann et al. (1986) as

$$
L=2 \mu \sqrt{\frac{3 \delta}{\left(1.5(2 K) /\left(\prod \mu\right)\right) \sum \rho}}
$$

where $\delta=$ spring deformation and $\mu, 2 K /(\pi \mu)$, and $\sum \rho$ are constants. 


\section{ait \\ ENERGY MATERIALS}

M A N E Y publishing

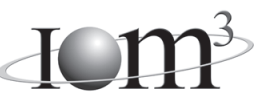

\section{Materials Science \& Engineering for Energy Systems}

Maney Publishing on behalf of the Institute of Materials, Minerals and Mining

The Institute of Materials, Minerals \& Mining

Economic and environmental factors are creating ever greater pressures for the efficient generation, transmission and use of energy. Materials developments are crucial to progress in all these areas: to innovation in design; to extending lifetime and maintenance intervals; and to successful operation in more demanding environments. Drawing together the broad community with interests in these areas, Energy Materials addresses materials needs in future energy generation, transmission, utilisation, conservation and storage. The journal covers thermal generation and gas turbines; renewable power (wind, wave, tidal, hydro, solar and geothermal); fuel cells (low and high temperature); materials issues relevant to biomass and biotechnology; nuclear power generation (fission and fusion); hydrogen generation and storage in the context of the 'hydrogen economy'; and the transmission and storage of the energy produced.

As well as publishing high-quality peer-reviewed research, Energy Materials promotes discussion of issues common to all sectors, through commissioned reviews and commentaries. The journal includes coverage of energy economics and policy, and broader social issues, since the political and legislative context influence research and investment decisions.

\section{CALL FOR PAPERS}

Contributions to the journal should be submitted online at http://ema.edmgr.com

To view the Notes for Contributors please visit: www.maney.co.uk/journals/notes/ema

Upon publication in 2006, this journal will be available via the Ingenta Connect journals service. To view free sample content online visit: www.ingentaconnect.com/content/maney

For further information please contact:

Maney Publishing UK

Tel: +44 (0)113 2497481 Fax: +44 (0)1132486983 Email: subscriptions@maney.co.uk

or

Maney Publishing North America

Tel (toll free): 8662975154 Fax: 6173546875 Email: maney@maneyusa.com

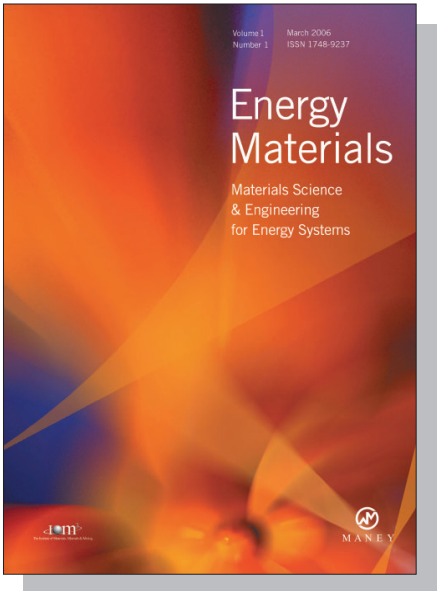

EDITORS

Dr Fujio Abe

NIMS, Japan

Dr John Hald, IPL-MPT, Technical University of Denmark, Denmark

Dr R Viswanathan, EPRI, USA

\section{SUBSCRIPTION INFORMATION}

Volume 1 (2006), 4 issues per year

Print ISSN: 1748-9237 Online ISSN: 1748-9245

Individual rate: $£ 76.00 / U S \$ 141.00$

Institutional rate: $£ 235.00 /$ US $\$ 435.00$

Online-only institutional rate: $£ 199.00 / U S \$ 367.00$

For special $\mathrm{IOM}^{3}$ member rates please email

subscriptions@maney.co.uk

\section{For further information or to subscribe online please visit www.maney.co.uk}



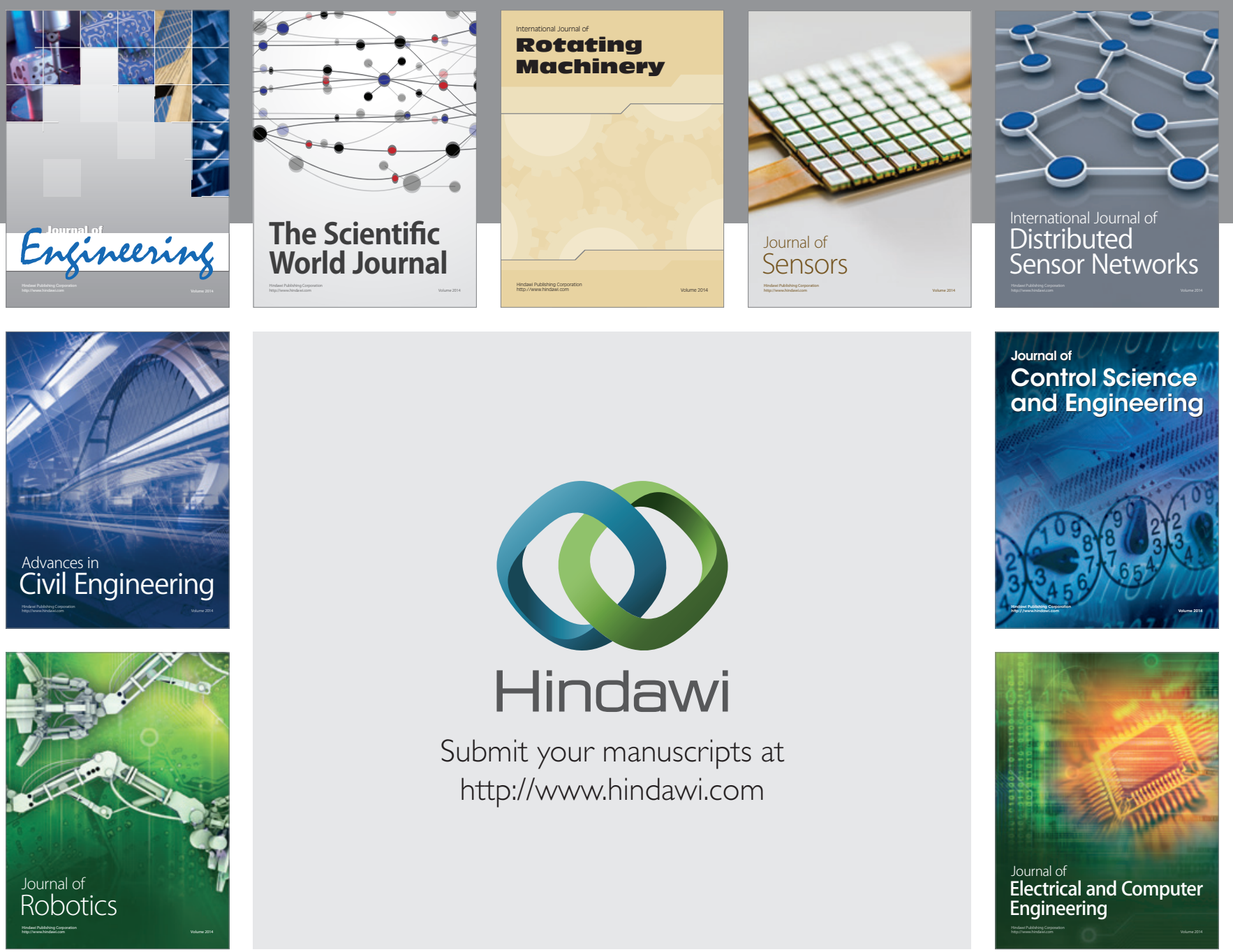

Submit your manuscripts at

http://www.hindawi.com
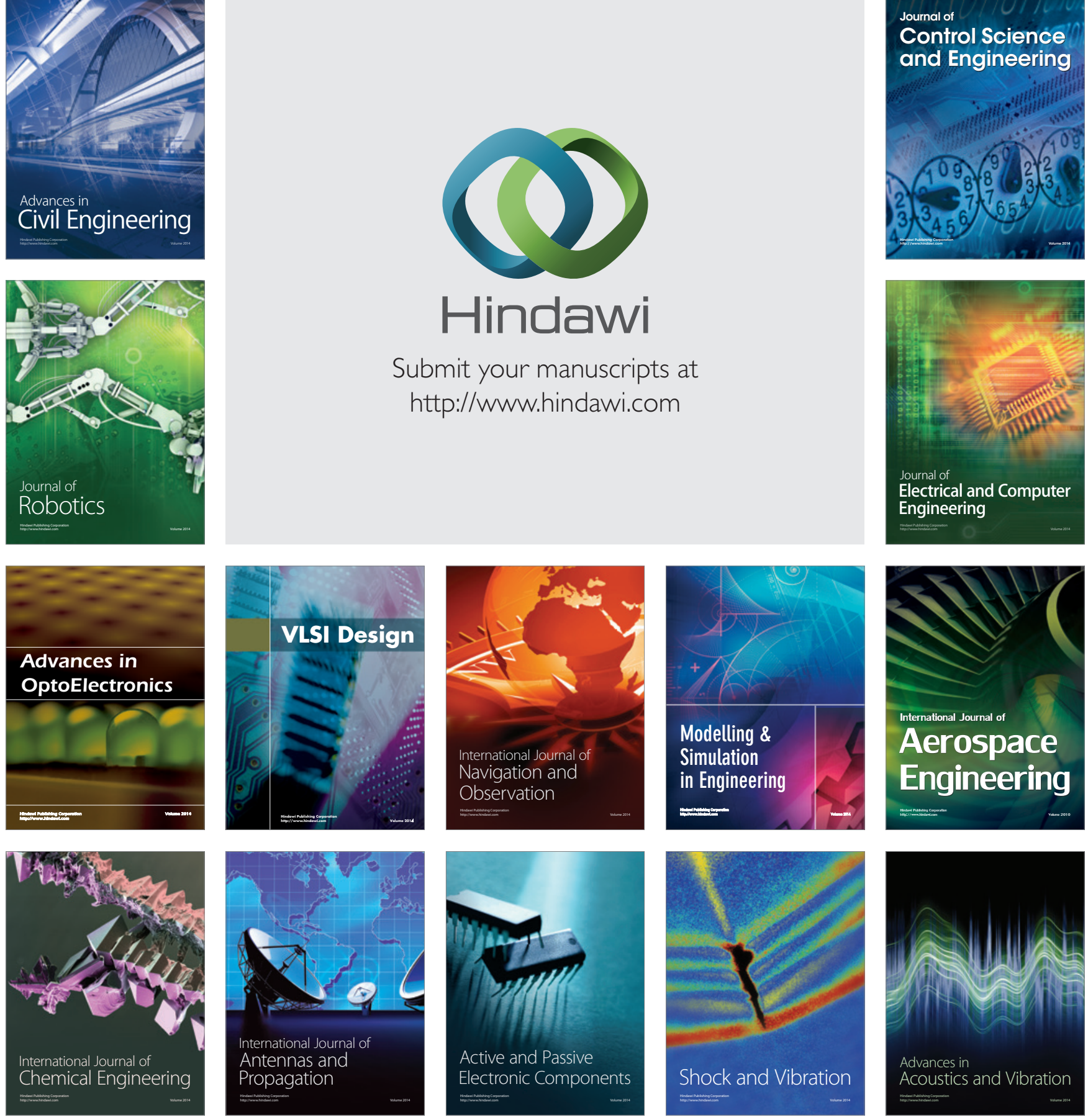